\begin{tabular}{|c|c|c|}
\hline 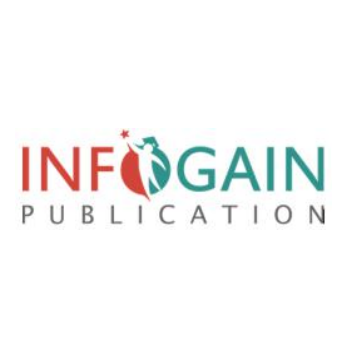 & $\begin{array}{l}\text { International Journal of Advanced Engineering, Management } \\
\text { and Science (IJAEMS) } \\
\text { ISSN: 2454-1311 } \\
\text { Vol-7, Issue-1; Jan, } 2021 \\
\text { Journal Home Page Available: } \text { https://ijaems.com/ } \\
\text { Journal DOI: https://dx.doi.org/10.22161/ijaems } \\
\text { Article DOI: https://dx.doi.org/10.22161/ijaems.71.7 }\end{array}$ & 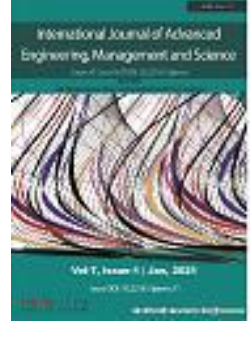 \\
\hline
\end{tabular}

\title{
An Assessment on the Factors Influencing Consumers' Participation in Social Commerce in Time of Pandemic
}

\author{
Cris Norman P. Olipas ${ }^{1}$, Jessamee G. Banay ${ }^{2,3}$
}

\author{
${ }^{1}$ Instructor, College of Information and Communications Technology, Nueva Ecija University of Science and Technology, Cabanatuan \\ City, Philippines \\ ${ }^{2}$ Instructor, College Department, Our Lady of the Sacred Heart College of Guimba, Inc, Guimba, Philippines \\ ${ }^{3}$ Student, Graduate School, Nueva Ecija University of Science and Technology, Cabanatuan City, Philippines
}

Received: 18 Nov 2020; Received in revised form: 05 Jan 2021; Accepted: 18 Jan 2021; Available online: 28 Jan 2021

(C)2021 The Author(s). Published by Infogain Publication. This is an open access article under the CC BY license

(https://creativecommons.org/licenses/by/4.0/).

\begin{abstract}
The study aims at assessing the factors influencing consumer participation in social commerce sites in times of pandemic. Respondents came from a first-class and third-class municipality in the province of Nueva Ecija, Philippines. Descriptive-Correlational research was utilized to describe the common factors that influence the consumers' participation in social commerce sites and correlate whether there is a significant difference between the assessments made. One hundred and five respondents participated in this study. Results revealed that social commerce components, perceived usefulness, reputation, and perceived ease of use are among the factors which significantly influence consumers to engage and participate in social commerce sites. Further, results revealed no significant difference between the assessments made from the first and third-class municipalities.
\end{abstract}

Keywords-Descriptive-Correlational, Pandemic, Social Commerce, Web 3.0.

\section{INTRODUCTION}

The dawn of Information Technology (IT) has brought significant impacts in the field of business. Businesses have given opportunities for IT tools and solutions to be utilized and become more effective. With the advancements of new technological innovations, businesses are given a wide range of opportunities to reach greater heights. Information Technology has been considered one of the essential components in a business environment (Albertin and De Moura, 2004). Information Technology provides tangible and intangible benefits to big and small businesses to make them more profitable and meet consumers' growing needs (Doane, 2018). Effective communication, reduction of costs, improved quality of consumer services, increased productivity and efficiency through automated business processes and solutions, improved operations and procedures such as efficient inventory and data management, as well as an improved management information system, and providing an opportunity for the development of innovative products for new markets are some of the roles of IT in the business sector (Feroz, 2018; Nikoloski, 2014; Kumar, 2014). Information Technology in businesses offers an opportunity for globalization, improved communication, achieved cost-effectiveness, bridge cultural gap, and creation of new jobs (Kumar, 2014). These advantages of IT in the business sector paved the way for continuous advancements and innovations.

The internet plays a vital role in businesses in this modern era. From the development of Web 1.0 in 1989 by Tim Berners-Lee (Berners-Lee, 1998), to the brainstorming done by O'Reilly and Media Live International to understand Web 2.0 (O'Reilly, 2006), up to the introduction of Web 3.0 in 2006 (Spivack, 2011), the internet has evolved and improved to cater the changing needs of consumers and to provide innovations to businesses and other sectors of the society. Today, Web 3.0 focuses on improving data 
management, supporting accessibility of mobile internet, stimulating creativity and innovation, encouraging factors of globalization phenomena, enhancing consumers' satisfaction, and organizing collaboration in the social web (Choudhury, 2014). The present era reaps the positive impacts of the developments made to harmonize the different business processes and procedures.

According to Garrigos-Simo (2012), Web 3.0 covers new technologies that are beneficial for firms to gather data before, during, and after interaction with consumers from diverse social networks or via the internet, in general, using techniques such as data warehousing, data mining, and customer relationship management. The collected data are turned into meaningful information vital for providing personalized products, brands, and services by and for different users according to their own needs. This capability of Web 3.0 provides a more effective way of doing business. One of the significant impacts of Web 3.0 is the continuous improvement of Social Networking Sites (SNS). The consumers' engagement in online exchange relationships with web vendors is commonly known as ecommerce (Paylou and Fygenson, 2006). Today, with the continued improvement to e-commerce and social networking sites through Web 3.0, new business opportunities aroused. The combination of social networking sites and e-commerce resulted in what is commonly known as social commerce. Social commerce is one of the emerging trends in e-commerce (Soleimani, Danaei, Jowkar, and Parhizgar, 2017). It is a subset of ecommerce wherein social commerce contains different kinds of business activities performed in different social media platforms which support social interactions and users' active participation and contribution to assist consumers in online buying and selling of products and services (Hajli et al., 2015; Chen and Shen, 2015; Lam et al., 2019; Stephen and Toubia, 2010). This has been supported by Maia et al. (2018), adding that the increased popularity of social networks has created business opportunities, leading to what is commonly known as social commerce.

Business activities include facilitating buying and selling of products and services and improving the quality of service being offered to different types of consumers (Kim and Park, 2013; Ng, 2013). Web 3.0 enables consumers to create their content (Philips, 2011). That is, social commerce becomes a valuable platform for consumers to share their own experiences about products and services offered to provide information to other consumers (Pitta and Fowler, 2005). Giving consumers' insights and feedback, either negative or positive, about a product or service, has been a useful activity to enhance and improve a social commerce firm's performance. Hence, word-of-mouth or WOM was identified as a unique means to increase consumers' trust in social commerce (Kim and Park, 2013). Social Commerce has two forms. First, social networking sites offer advertisements and transactions for buying and selling products and services, such as Facebook, Instagram, and Twitter. These platforms allow consumers to browse, compare and review products before placing an order to make a purchase. Comparative advertising contributes to consumer's social media engagement. Such engagement may be converted into actual purchases. Hence different social media platforms, while providing an opportunity to widen social networks, allows a potential consumer to become real buyers of products and services. Second, the traditional e-commerce wherein consumers have to visit the site to see the products and services to know more about them like Lazada, Shopee, and Zalora (Rosa, Dolci, and Lunardi, 2014). Many consumers tend to become "visual buyers," graphics and presentations play an essential role in persuading and convincing consumers. Companies create websites with good graphic design and visually engage infographics to entice people to stay on their website. Social Commerce paves a way to market development, in which indicators and sources are undeniably based on consumer's loyalty. When consumers see prices are reasonable, in line with quality, and reflected with market-based pricing, consumer's loyalty, as well as enthusiasm, is a boost.

Liang and Turban (2011) explain that social commerce has three attributes. This includes the presence of media technologies, community interactions, and commercial activities. On the other hand, Swami (2019) cites the different characteristics of Social Commerce. In social commerce, consumers have the power to buy and try products and services based on the descriptions provided by the seller and based on social reviews by other users; Consumers actively participate in giving feedback for products and services. This characteristic of social commerce enables the seller to closely monitor the product or service to correct possible flaws or problems encountered by consumers as reflected in their feedback. Sharing of information about products and services becomes easier through different social networking sites like Facebook and Twitter. Because of Web 3.0, consumers are now offered products and services similar to their interest and purchased items; Multimedia elements such as pictures, audio, and videos play a vital role in marketing the product or service. Social commerce provides a venue to facilitate these added features, and Multimedia elements such as pictures, audio, and videos play a vital role in marketing the product or service. That is, social commerce provides a venue to facilitate these added features.

Several studies have been undertaken to draw valuable insights into social commerce further. One of which was Friedrich (2016), who performed a systematic review of 61 
academic publications to provide a structured and comprehensive list of factors and their potential effects on various adoption-related outcome variables. While several empirical studies have been conducted, the present research aims to contribute to the existing pool of literature to help fill in gaps. Companies are highly interested in identifying essential information relevant to effectively deploy social commerce to increase their sales (Friedrich, 2016; Zhou, Zhang, and Zimmermann, 2013; Stephen and Toubia, 2010). Several companies continuously work on how to figure out the different factors influencing consumers to participate in social commerce (Zhou, Zhang, and Zimmermann, 2013; Zhan et al., 2014; AlfieriLucas, 2015). Hence, this study may provide relevant information about the essential factors and the relevant information needed by companies engaging in social commerce.

In the systematic review done by Friedrich (2016), it is essential to conduct a study to examine the importance of the factors that are have only been examined in the systematic review and to combine the identified factors and outcomes variables to develop a complete understanding of the consumer's adoption of social commerce. Considering the stated gaps identified, the present study aims to assess the factors influencing consumers' participation in Social Commerce via Web 3.0. This study was conducted in the time of pandemic to further analyze the consumer's participation and engagement from a first-class municipality and a third class municipality in the Province of Nueva Ecija, Philippines.

\subsection{Statement of the Problems}

In general, this study sought to assess the factors influencing consumers' participation in Social Commerce. Specifically, it aimed to answer the following:

1. How may the demographic profile of the respondents be described in terms of:

1.1. Sex;

1.2. Age

\subsection{Civil Status?}

2. How may the respondents response be described in terms of the following social commerce aspects:

\subsection{Frequently Used Social Networking Sites;}

2.2. Average Amount Range of Purchased Products;

2.3. Type of Products Frequently Purchased?

3. How may the consumers' participation in Social Commerce be described in terms of the following factors:

3.1. Information Quality;

3.2. Perceived Ease of Use;

3.3. Perceived Usefulness;

3.4. Product Delivery;

3.5. Reputation;

3.6. Social Commerce Component;

3.7. Trust;

3.8. Transaction Safety?

4. Is there a significant difference between the participation in social commerce and the classification of municipality where they reside?

\subsection{Scope and Limitations}

This study focused on assessing the factors influencing consumers' participation to social commerce in Web 3.0 to understand which factors significantly affect their intention to participate. It covers the factors identified in the study of Maia et al. (2018), which include information quality, perceived ease of use, perceived usefulness, product delivery, reputation, social commerce component, trust, and transaction safety. Two municipalities in the province of Nueva Ecija participated in this study. Municipality A is a first-class municipality, while Municipality B is a third class municipality. Two different municipality classifications were included to see how the respondents from the respective municipalities participated in social commerce to provide a deeper understanding and broader perspective. The target number of samples was 120 respondents. However, due to the pandemic, one hundred five respondents were able to participate in the study. The respondents who participated in this study have experienced using different social commerce websites such as Lazada, Shopee, and Zalora. The results did not provide a generalization of the entire population; instead, it only provides a view of how the respondents assessed the factors influencing consumers' social commerce participation in Web 3.0.

\section{METHODOLOGY}

\subsection{Research Design}

A quantitative type of research was used to identify and assess the factors influencing the consumers' involvement in social commerce. Quantitative research is a method of research that relies on measuring the variables involved using numerical systems. Results of measuring variables are treated and analyzed using statistical models and tools. Relationships and associations of variables under investigation can be revealed using statistical treatments 
(Alfieri-Lucas, 2015). In this study, a combination of descriptive and correlational research design was utilized to describe and measure the relationship of the variables under investigation. According to Quaranta (2017), a descriptive-correlational research design does not need to establish a causal connection among variables for its main focus to describe and measure their relationship.

\subsection{Research Locale, Respondents, and Sampling Procedures}

This study was conducted in the province of Nueva Ecija, Philippines. Situated in Central Luzon, the province is nationally known as the "Rice Granary of the Philippines." The researchers wanted to assess the factors influencing consumers' participation in social commerce in the context of an area where agriculture is one of the major industries to see how social commerce can be of a possible potential innovation that can be implemented and contribute to the growth of the economy of the province. The researchers utilized a non-probabilistic sampling method because respondents must have experienced using a social commerce site. A non-probabilistic sample is a sampling technique where the possibility of being selected cannot be calculated (Stephanie, 2015). That is, members of the population need to satisfy specific qualifications before being considered a respondent. Purposive sampling was used since the researchers identified the population members who have experienced using social commerce site. According to Stephanie (2015), purposive sampling is a technique where the researchers know the study and the population. Thus the possible respondents are already identified based on the criteria that need to be satisfied.

\subsection{The Research Instrument and Procedure of the Study}

The research instrument used was based on Maia et al. (2018), but it was modified to suit the current study's needs. After the researchers constructed the instrument, they distributed them to the respondents. Using the Social Networking Site - Facebook, the researchers sent the survey questionnaire to their Facebook friends who have agreed to be part of this study. The respondents must be eighteen years old and above and have experienced searching and buying products and services to a social commerce site. The researchers ensure that the respondents have understood this study's purpose and willingly participated as respondents. They also explained and assured the respondents that the data gathered were collected, organized, treated, and kept for research purposes only and with the utmost confidentiality.

\subsection{Data Analysis}

In analyzing the gathered data for this study, the researchers used a statistical software tool such as SPSS to organize and treat the data to provide more meaningful information. A rubric was also used as a scoring guide in this study, as presented in Table 1.

Table 1: Scoring Rubric

\begin{tabular}{cc}
\hline Range & Verbal Interpretation \\
\hline $3.26-4.00$ & Strongly Agree \\
$2.51-3.25$ & Agree \\
$1.76-2.50$ & Disagree \\
$1.00-1.75$ & Strongly Disagree \\
\hline
\end{tabular}

\section{RESULTS AND DISCUSSION}

\subsection{The Demographic Profile of the respondents based on Sex, Age, and Civil Status}

\subsubsection{The percentage distribution based on Sex}

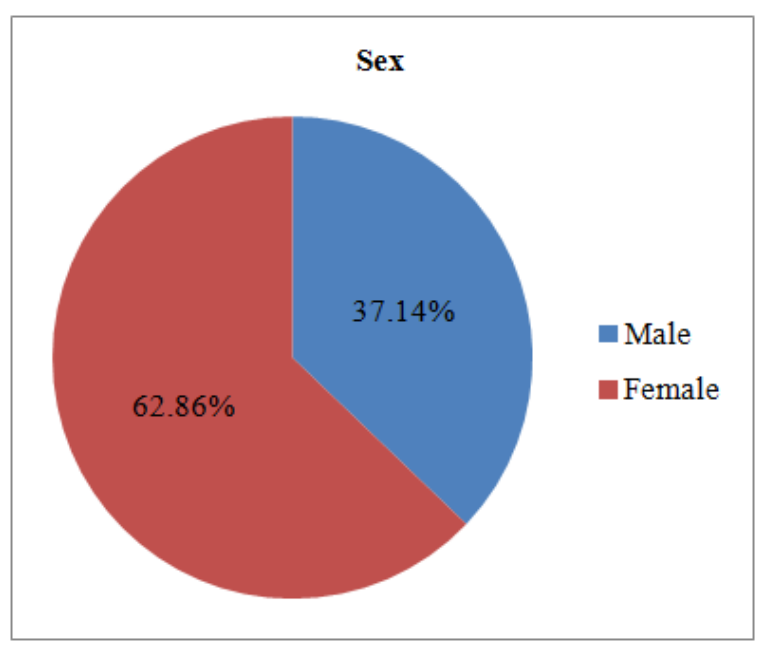

Fig. 1: The frequency distribution according to Sex

Out of one hundred five (105) respondents who participated in this study from the two municipalities in the province of Nueva Ecija, $62.86 \%$ were female, and $37.14 \%$ were male. Results show a $25.72 \%$ difference between the participation of both sexes, revealing that more females were engaged in social commerce than males. Men are more likely to be online, but females shop more. A little over $50 \%$ of the internet population was male. However, $58 \%$ of e-commerce revenue comes from females (pfscommerce.com, 2012). Based on this study's results, females in both municipalities were more likely to engage in social commerce. Thus generalization may be drawn that regardless of the municipality they came from, females engage more in social commerce.

\subsubsection{The percentage distribution based on Age}




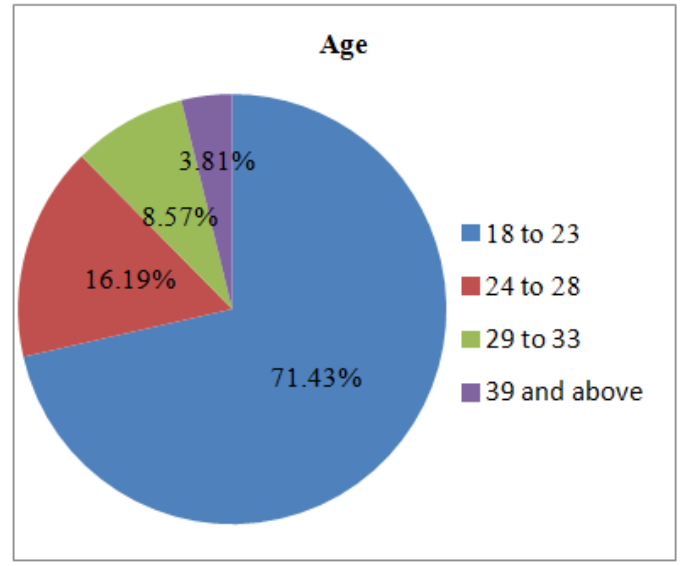

Fig. 2: The frequency distribution according to Age

Figure 2 presents the distribution according to the respondents' age. Results show that $71.43 \%$ of the respondents fell on the 18 to 23 age bracket, followed by $16.19 \%$ from the 24 to 28 age bracket. An $8.57 \%$ and $3.81 \%$ came from 29 to 33 and 39 and above age brackets, respectively. Wertz (2019) asserts that Generations X and $\mathrm{Z}$ shop 2-3 times more on social channels than the average consumer. Results suggest that consumers in the youngest bracket tend to engage more in social commerce because of their social media exposure, higher engagement to different social networking sites, and the increasing promotion of different businesses to capture the younger generation's interest.

\subsubsection{The percentage distribution based on Civil} Status

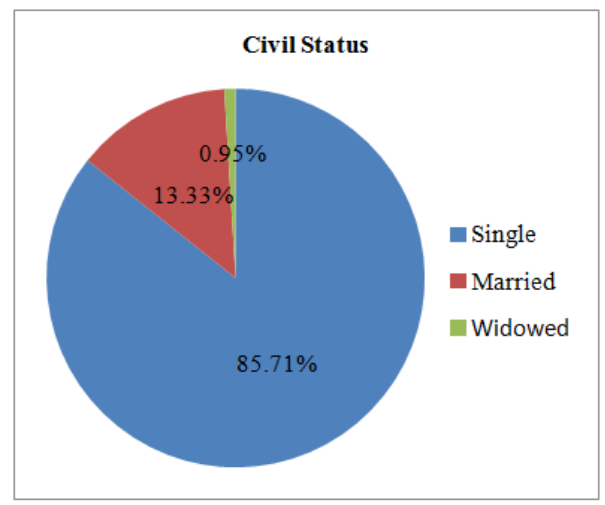

Fig. 3: The frequency distribution according to Civil Status

The percentage distribution according to civil status shows that $85.71 \%$ of the respondents were single, $13.33 \%$ were married, and $0.95 \%$ was widowed. Considering the percentage distribution based on age as shown in Figure 2, the youngest age bracket got the highest percentage; results based on civil status confirmed that the respondents who participated in this study belong to the younger generation comprised of students and young professionals who are single.

\subsection{Understanding Respondents in different Social Commerce Aspects}

\subsubsection{Frequently Used Social Networking Sites}

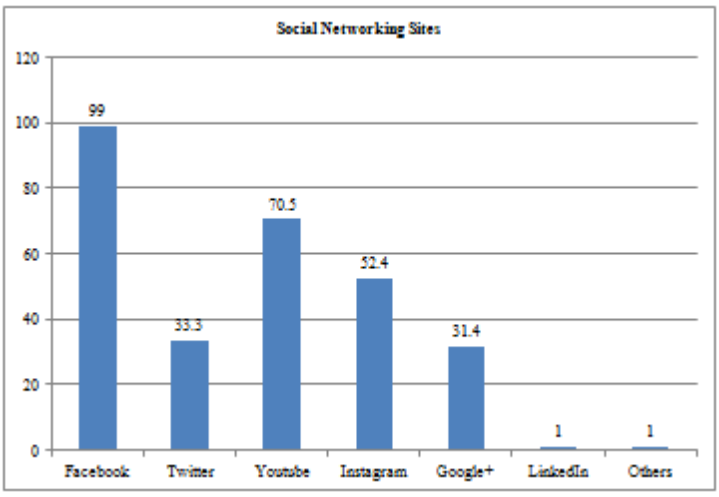

Fig. 4: The frequency distribution according to the frequently used social networking sites

Figure 4 shows the frequently used social networking sites of the respondents from the two municipalities. Facebook got the highest rank, followed by YouTube, Instagram, and Twitter. Results suggest that to increase consumers' engagement to social commerce further, businesses should further improve and increase their online activities in these platforms because consumers are engaging more of their time to these platforms. Ortiz-Ospina (2019) affirms that Facebook is the largest social media platform globally, followed by YouTube and Whatsapp. These social media platforms are used by one-in-three people globally, providing more and more opportunities for business entities for social commerce.

\subsubsection{Average Amount Spent in Purchasing Items to} Social Commerce Sites

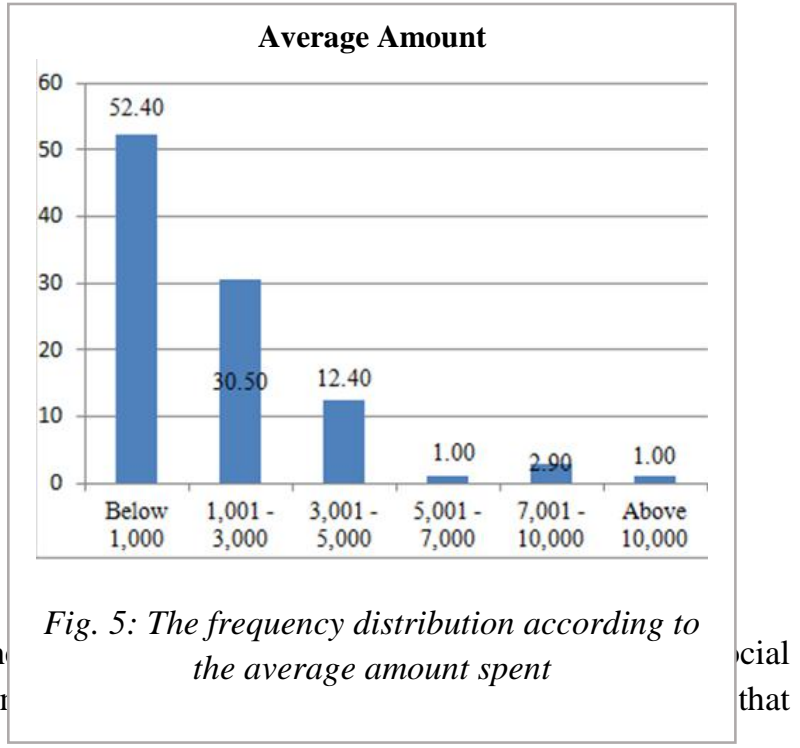


$52.40 \%$ of the respondents spend $\mathrm{Php1,000}$ and below, $30.50 \%$ spends Php1,001 to Php3,000, 12.40\% spends Php3,0001 to Php5,000, 1\% spends Php5,001 to Php7,000, $2.90 \%$ spends Php7,001 to Php10,000, and 1\% spends Php10,000 and above. Most respondents do not spend much on social commerce sites, which agrees with the demographic profile based on age. The respondents who participated in this study mostly were students and young professionals that may have limited financial resources but experienced purchasing in social commerce sites.

\subsubsection{Type of Products Frequently Purchased to Social} Commerce Sites

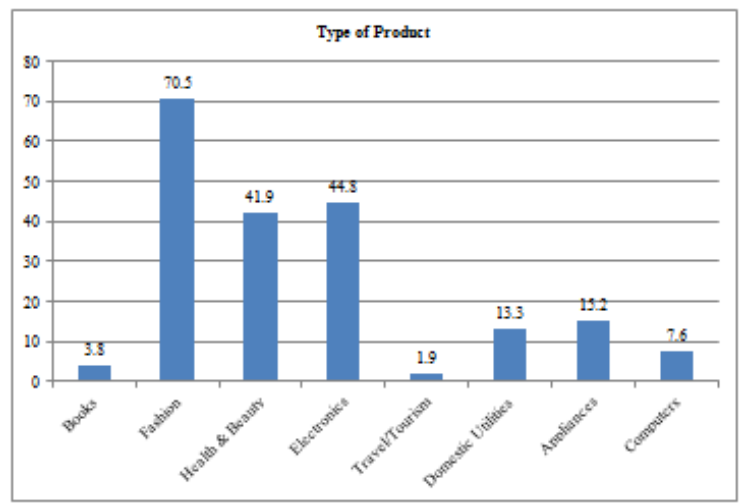

Fig. 6 The frequency distribution of average amount spent in social commerce sites

Figure 6 shows the type of products frequently purchased on social commerce sites. Results show that Fashion (70.5\%), Electronics (44.8\%), and Health and Beauty $(41.9 \%)$ are the top three product categories commonly purchased by the respondents. Meanwhile, products and services relating to travel and tourism $(1.9 \%)$ and books $(3.8 \%)$ are the least commonly purchased by the respondents. This study's results affirm Sabanoglu (2020), indicating that clothing, shoes, and consumer electronics are the commonly purchased products online.

\subsection{The Factors in Social Commerce Participation}

Table.2: Factors influencing consumer's participation in social commerce

\begin{tabular}{lcc}
\hline \multicolumn{1}{c}{ Factors } & Mean & Rank \\
\hline Information Quality & 3.04 & 8 \\
Perceived Ease of Use & 3.19 & 4 \\
Perceived Usefulness & 3.36 & 2 \\
Delivery & 3.16 & 5 \\
Reputation & 3.29 & 3 \\
Social Commerce Components & 3.37 & 1 \\
Trust & 3.15 & 6 \\
Transaction Safety & 3.08 & 7 \\
\hline
\end{tabular}

Table 2 presents the respondents' assessment from the two municipalities on the common factors influencing consumers' participation in social commerce in the time of the pandemic. The factor involving the social commerce sites' components got the highest rank with a mean rating of 3.37. These social commerce components include the ratings, reviews, and recommendations given by different site visitors and consumers about the different products and services. These ratings, reviews, and recommendations contribute to increasing consumers' participation in different social commerce sites. Based on the respondents ' assessment, garnering the next highest rank was the site's perceived usefulness with a mean rating of 3.36. Search Engine Optimization (SEO) is a useful tool incorporated in different social commerce sites that adds to its overall usefulness. The site's ability to provide accurate search results and recommend related products to consumers increases the site's usability and effectiveness. Another factor that users consider when engaging in social commerce is the company's reputation. Based on the assessment made, reputation as a factor got a mean rating of 3.29. The name and the brand of the social commerce company are essential factors to increase the consumers' participation.

On the other hand, perceived ease of use with a mean rating of 3.19 is another factor considered by the respondents as an essential contributory factor when participating and engaging in social commerce sites. Social commerce sites must be easily navigated in order to increase consumers' participation. Its user interface (UI) must be user-friendly, and visitors on the site must have a worthwhile user experience (UX) to increase site visitors and consumers' engagement and participation.

Factors relating to Delivery $(\mathrm{WM}=3.16)$, Trust $(\mathrm{WM}=$ 3.15), Transaction safety ( $\mathrm{WM}=3.08)$, and Information Quality (WM = 3.04) are the four least factors based that contributes to consumers participation and engagement to social commerce based from the assessment made by the respondents. While these factors may have low mean ratings, it is still important to consider these factors to increase consumers' participation and engagement to social commerce sites.

\subsection{The Difference in Social Commerce Participation of Two Municipalities}


Table.3: Difference of Two Municipalities in Social Commerce Participation

\begin{tabular}{ccc}
\hline \multirow{2}{*}{ Mean } & Municipality A & 3.22 \\
& Municipality B & 3.20 \\
\hline \multirow{2}{*}{ t-value } & .253 \\
df & 103 \\
p-value & .801 \\
\hline \multirow{2}{*}{ Interpretation } & No Significant \\
& Difference \\
\hline
\end{tabular}

Table 3 presents the test of difference made by the researchers on the respondents' social commerce participation from the two municipalities. Results revealed no significant difference between their social commerce participation in the time of the pandemic. This indicates that regardless of the municipality they reside (i.e. 1st class and 3rd class municipalities), their intention, engagement, and participation in social commerce sites do not differ. The type of municipality where the respondents reside does not contribute to their active participation in the social commerce site. Hence, it is essential to note that other factors may affect the consumers' participation in social commerce sites, but the type of municipality does not contribute, especially in pandemics.

\section{CONCLUSION}

This study aimed at assessing the factors influencing the consumers' participation to social commerce in time of pandemic. It was found out that females engage and participate more in social commerce sites compared to males. The younger generation of consumers is more active in engaging with different social commerce sites due to their higher exposure to different sites and more technologies. Further, results revealed that those who were single actively use social commerce sites and that an affordable amount was spent ranging from 1,000 pesos and below. In terms of the factors influencing the consumers' participation, it was found out that social commerce components, perceived usefulness, reputation, and perceived ease of use were among the factors that contribute to consumers' higher engagement. In testing the difference between the participation of consumers considering the municipality where they reside, whether first class or third class municipality, it was found out that there is no significant difference in their participation indicating that regardless of the municipality of the place where consumers' reside, their engagement and participation to social commerce sites were not affected.

\section{RECOMMENDATIONS}

Based on the conclusions drawn, the following are some of the recommendations of this study:

1. The study may be conducted in a much larger locale involving different types of respondents from different walks of life to draw new insights;

2. New entrepreneurs may use the results of this study to understand their prospective customers;

3. Micro, Small, and Medium Enterprises may look into how respondents of this study participate in social commerce, considering the factors involved in drawing new insights to improve their business.

\section{REFERENCES}

[1] Albertin, A. and De Moura, R. (2004). The Benefits of Information Technology in Business Performance. AMCIS 2004. Proceedings. Paper 121. Available at https://www.aisel.aisnet.org/amcis2004/121.

[2] Doane, J. (2018). Business and its relationship to technology. Intellinet. Available at https://www.intellinet-tech.com/businessand-its-relationship-with-technology/.

[3] Feroz, R. (2018). Advantages of technology in business. TechnoFAQ. Available https://www.technofaq.org/posts/2018/07/advantages-oftechnology-in-business/.

[4] Nikoloski, K. (2014). The Role of Information Technology in the Business Sector. International Journal of Science and Research (IJSR), 3(12) ISSN 2319-7064.

[5] Kumar, M. (2014). Information Technology: Roles, Advantages and Disadvantages. International Journal of Advanced Research in Computer Science and Software Engineering. 4(6). ISSN 2277-128X, 020-1024.

[6] Berners-Lee, T. (1998). The World Wide Web. A very short personal history. Available at https://www.w3.org/people/berners-lee/shorthistory.html.

[7] O'Reilly, T. (2006). Definition of Web 2.0. Available at https://www.radar.oreilly.com/archives/2006/12/web-20compact-definition-tryi.html.

[8] Spivack, N. (2011). Web 3.0: The Third Generation Web Is Coming. Available at https://www.lifeboat.com/ex/web.3.0.

[9] Choudhury, N. (2014). World Wide Web and Its Journey from Web 1.0 to Web 4.0. International Journal of Computer Science and Information Technologies, 5(6), ISSN: 0975-9646, 80968100.

[10] Garrigos-Simo, F. (2012). Social networks and Web 3.0: Their Impact on the management and marketing of organizations. Management Decisions. 50(10), Emerald Group Publishing Limited. P. 1880-1890 10.1108/00251741211279657.

[11] Pavlou, P.A and Fygenson, M. (2006). Understanding and predicting electronic commerce adoption: an extension of the theory of planned behavior. MIS Quarterly. 3(1), 115-143. 10.2307.25148720. 
[12] Soleimani, M., Danaei, H., Jowkar, A., and Parhizgar, M. (2017). Factors Affecting Social Commerce and Exploring the Mediating Role of Perceived Risk (Case Study: Social Media Users in Isfahan). Iranian Journal of Management Studies. 10(1), 66-90, 10.22059/ijms.2017.212223.672191.

[13] Hajli, N., Shanmuganm, M., Powell, P., and Love, P.E. (2015). A study on the continuance participation in on-line communities with social commerce perspective. Technological Forecasting and Social Change. 96, 232-241.

[14] Chen, J., and Shen, X, -L, (2015). Consumer's decisions in social commerce context: An empirical investigation. Decision Support Systems, 79, 55-64, 10.1016/j.dss.2015.07.012.

[15] Lam, H et al (2019). Should Firms Invest in Social Commerce? An Integrative Perspective. Information \& Management. 56(8): 103164. 10.1016/j.im.2019.04.007.

[16] Stephen, A.T and Toubia, O. (2010). Deriving value from social commerce network. Journal of Marketing Research. 47(2), 215$228,10.1509 / j \mathrm{jkr} .47 .2 .215$.

[17] Maia, C., Lunardi, G., Longaray, A., and Munhoz, P. (2018). Factors and characteristics that influence consumers' participation in social commerce. Revista de Gestao. 25(2) 2018. 194-211. Emerald Publishing Limited. 2177-8736. 10.1108/REGE-03-2018-031.

[18] Kim, S., and Park, H. (2013). Effects of various characteristics of social commerce (s-commerce) on consumers' trust and trust performance. International Journal of Information Management. 33(2), 318-332.

[19] Ng, C.S. -P. (2013). Intention to purchase on social commerce websites across cultures: A cross-regional study. Information \& Management, 50(8), 609-620, 10.10169/j.im.2013.08.002.

[20] Philips, F. (2011). The state of technological and social change: Impressions. Technological Forecasting and Social Change. 78(6), 1072-1078.

[21] Pitta, D.A., and Fowler, D. (2005). Online consumer communities and their value to new product developers. Journal of Product \& Brand Management, 14(5), 283-291.

[22] Rosa, R.A., Dolci, D.B., and Lunardi, G.L. (2014). Social Commerce: Estado da Arte e Oportunidades de Pesquisa. Anais do Encontro Nacional da Associacao Nacional De PosFraduacao e Pesquisa em Administracao, Rio de Janeiro p. 28.

[23] Liang, T.P and Turban, E. (2011). Introduction to the special issue social commerce: a research framework for social commerce. International Journal of Electronic Commerce. 16(2) 5-14 10.2753/JEC1086-4415160201.

[24] Swami, J. (2019). The 7 Characteristics of Social Commerce. Available at https://www.uberdigit.com/the-7-characteristics-ofsocial-commerce/.

[25] Friedrich, T. (2016). On the factors influencing consumer's adoption of social commerce - a review of the empirical literature. Pacific Asia Journal of the Association for Information Systems. 8(4), 1-32 Available at https://www.journal.ecrc.nsysu.edu.tw/index.php/pajais/article/vi ew/379/179.

[26] Zhou, L., Zhang, P., and Zimmermann, H.D. (2013). Social commerce research: an integrated view. Electronic commerce research and applications. 12(2), 61-68, 10.106/j; :elerap.2013.02.003.
[27] Stephen, A.T., and Toubia, O. (2010). Deriving value from social commerce networks. Journal of Marketing Research, 47(2), 215-228, 10.1509/jmkr.47.2.215.

[28] Turban, E., Bolloju, N., and Liang, T.P. (2010). Social Commerce: an e-commerce perspective. Proceedings of the $12^{\text {th }}$ International Conference on Electronic Commerce: Roadmap for the Future of Electronic Business, ACM, August, 33-42, 10.1145/2389376.2389382.

[29] Zhang, H., Lu, Y., Gupta, S., and Zhao, L. (2014). What motivates customers to participate in social commerce? The impact of technological environment and virtual customer experiences. Information \& Management, 51(8), 1017-1020, 10.1016/j.im.2014.07.005.

[30] Alfieri-Lucas, D. (2015). Marketing the $21^{\text {st }}$ Century Library. Chandos Publishing. ISBN 978-1-84334-773-6. 10.1016/C20140-02558-0.

[31] Quaranta, J. (2017). Descriptive Correlational Research: Asthma Management by School Nurse. SAGE Research Methods Cases in Health. 10.4135/9781526407696.

[32] Stephanie (2015). Non-Probability Sampling: Definition, Types. Available at https://www.statisticshowto.datasciencecentral.com/nonprobability-sampling/.

[33] Stephanie (2015). Purposive Sampling. Available at https://www. .statisticshowto.datasciencecentral.com/purposivesampling/.

[34] pfscommerce.com (2012). Understanding Gender and Commerce. Available at https://www.pfscommere.com/blog/understanding-genderand-ecommerce/

[35] Wertz, J. (2019). Why the Rise of Social Commerce is Inevitable. Retrieved https://www.forbes.com/sites/jiawerts/2019/06/25/inevitablerise-of-social-commerce.

[36] Ortiz-Ospina, E. (2019). The Rize of Social Media. Retrieved at https://www.ourworldindata.org/rise-of-social-media.

[37] Sabanoglu, T. (2020). Most Popular Online Shopping Categories Worldwide 2018. Retrieved from Leading online shopping categories worldwide 2018 | Statista 